\title{
Modelling harbour porpoise seasonal density as a function of the German Bight environment: implications for management
}

\author{
Anita Gilles ${ }^{1, *}$, Sven Adler ${ }^{1,2}$, Kristin Kaschner ${ }^{1,3}$, Meike Scheidat ${ }^{1,4}$, Ursula Siebert ${ }^{1}$ \\ ${ }^{1}$ Research and Technology Centre (FTZ), Christian-Albrechts-University of Kiel, 25761 Büsum, Germany \\ ${ }^{2}$ University of Rostock, Institute for Biodiversity, 18057 Rostock, Germany \\ ${ }^{3}$ Evolutionary Biology \& Ecology Lab, Institute of Biology I (Zoology), Albert-Ludwigs-University, 79104 Freiburg, Germany \\ ${ }^{4}$ Wageningen IMARES, Institute for Marine Resources and Ecosystem Studies, Postbus 167, 1790 AD Den Burg, \\ The Netherlands
}

\begin{abstract}
A classical user-environment conflict could arise between the recent expansion plans of offshore wind power in European waters and the protection of the harbour porpoise Phocoena phocoena, an important top predator and indicator species in the North Sea. There is a growing demand for predictive models of porpoise distribution to assess the extent of potential conflicts and to support conservation and management plans. Here, we used a range of oceanographic parameters and generalised additive models to predict harbour porpoise density and to investigate seasonal shifts in porpoise distribution in relation to several static and dynamic predictors. Sightings were collected during dedicated line-transect aerial surveys conducted year-round between 2002 and 2005. Over the 4 yr, survey effort amounted to $38720 \mathrm{~km}$, during which 3887 harbour porpoises were sighted. Porpoises aggregated in distinct hot spots within their seasonal range, but the importance of key habitat descriptors varied between seasons. Predictors explaining most of the variance were the hydrographical parameter 'residual current' and proxies for primary production and fronts (chlorophyll and nutrients) as well as the interaction 'distance to coast/water depth'. Porpoises preferred areas with stronger currents and concentrated in areas where fronts are likely. Internal cross-validation indicated that all models were highly robust. In addition, we successfully externally validated our summer model using an independent data set, which allowed us to extrapolate our predictions to a more regional scale. Our models improve the understanding of determinants of harbour porpoise habitat in the North Sea as a whole and inform management frameworks to determine safe limits of anthropogenic impacts.
\end{abstract}

KEY WORDS: Habitat modelling · Phocoena phocoena $\cdot$ Conservation · Generalised additive model · North Sea Resale or republication not permitted without written consent of the publisher

\section{INTRODUCTION}

From a legal perspective, it has recently been recognised that the relationship between the protection of cetaceans within the European Union (EU) on the one hand and the EU Common Fisheries Policy on the other constitutes a classic example of a user-environment conflict (Proelss et al. 2011). A similar problem might arise in the near future with the construction of more offshore wind farms (OWFs) in Europe (Gill 2005), which is clearly an important response to global warming and is in line with the obligation to move to renewable energy generation. Coastal zones, however, are already under significant pressure from human activity, and harbour porpoises Phocoena phocoena inhabiting shelf waters are threatened by by-catch in fisheries (Vinther \& Larsen 2004, Siebert et al. 2006), chemical (Siebert et al. 1999, Das et al. 2006, Beineke et al. 2007) and noise pollution (Richardson et al. 1995, Koschinski et al. 2003, Lucke et al. 2008, 2009). The 
harbour porpoise is among the most common cetaceans in the northern hemisphere (Hammond et al. 2002) and as such is an important top predator and indicator species. Changes in the environment are likely to be accommodated more readily by abundant top predators than by many other species. Particularly the construction of OWFs might have an impact, as source levels of pile driving are well above the auditory tolerance of P. phocoena (Lucke et al. 2009), and their zone of responsiveness (sensu Richardson et al. 1995) extends beyond $20 \mathrm{~km}$ (Gilles et al. 2009, Tougaard et al. 2009). All North Sea coastal states have major plans to increase their marine renewable energy production (e.g. in the German North Sea, 23 OWFs are already approved and 57 additional sites are in the approval process; see www.bsh.de/de/Meeresnutzung/ Wirtschaft/CONTIS-Informationssystem/ContisKarten/ NordseeOffshoreWindparksPilotgebiete.pdf; Fig. 1); within the next decade, construction activities will be carried out at several locations simultaneously, and these cumulative effects - in addition to recognised threats such as by-catch - can no longer be considered short term.

Moreover, the construction sites of several OWFs overlap spatially with marine special areas of conservation (SACs) designated under the EU Habitats Directive (Scheidat et al. 2006, Gilles et al. 2009), where Phocoena phocoena is listed in Annex II and IV. SACs are supposed to include the main core range of a national stock (Wilson et al. 2004), but the delimitation of SACs is challenging for highly mobile species such as the harbour porpoise (Embling et al. 2010). An important prerequisite for the implementation of a sound management plan for the entire North Sea is therefore the identification of hotspots across different seasons and years. However, suitable long-term data sets for this have not been available thus far. In addition, in view of future environmental changes that can

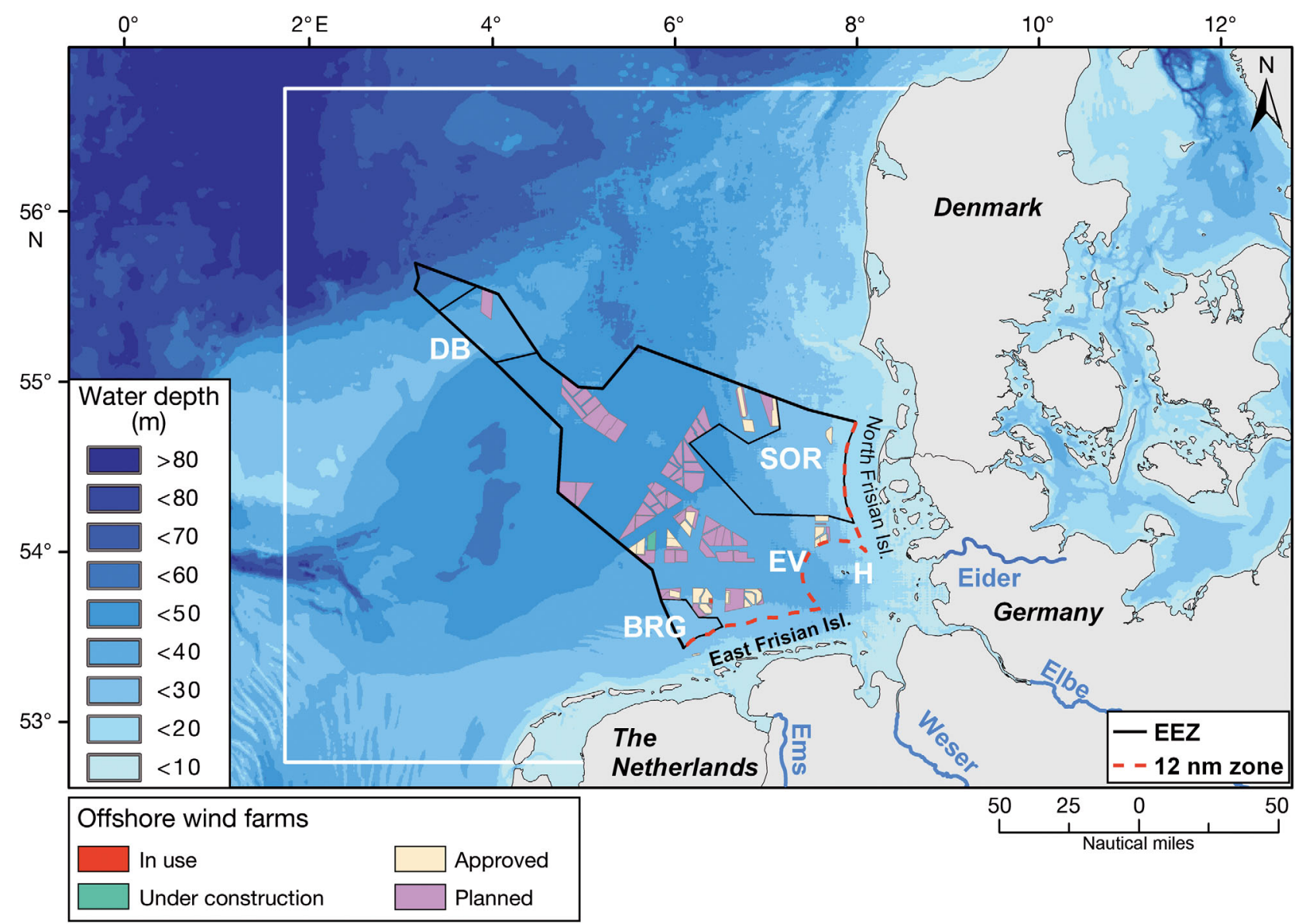

Fig. 1. Study area in the SE North Sea. Data on harbour porpoise distribution were collected in the German Exclusive Economic Zone (EEZ) and the 12 nautical mile $(\mathrm{nm})$ zone. Environmental data were compiled for a wider area, indicated by the white border. DB: Dogger Bank, BRG: Borkum Reef Ground, SOR: Sylt Outer Reef, EV: Elbe valley, H: island of Heligoland. The 3 special areas of conservation are indicated by solid black lines within the EEZ, and sites for offshore wind farms (OWF) source: www.bsh.de/de/Meeresnutzung/Wirtschaft/CONTIS-Informationssystem/ContisKarten/NordseeOffshoreWindparks Pilotgebiete.pdf) by different colours (see map legend) 
be expected as the result of global warming, the identification of factors that directly or indirectly determine porpoise occurrence is crucial for a long-term adaptive management approach that would be able to account for potential shifts in distribution.

Cetacean distribution patterns are most often determined by their response as predators foraging in a patchy prey resource environment (Redfern et al. 2006). This holds especially true for porpoises, which, due to their small size and their distribution in temperate waters, have a high energy demand but only limited energy storage capacities (Koopman 1998). As data on prey density are rarely available at the required spatial resolution to be used for habitat prediction models, we used physical and biological ocean properties as proxies for prey abundance.

While the ecological processes determining porpoise distribution are still not well understood, our knowledge of influencing factors has increased. Examples are water depth (MacLeod et al. 2007), tidal flow (Pierpoint 2008, Marubini et al. 2009) or upwelling zones (Skov \& Thomsen 2008). However, species may have different habitat preferences in different geographic regions, and investigations of environment correlates cannot be readily extrapolated beyond the original study area without external validation. Until now, no habitat prediction model has been developed for harbour porpoises in the German Bight.

The diet of porpoises is known to vary seasonally (Santos \& Pierce 2003, Gilles 2009), and we can therefore expect the functional relationship between porpoise occurrence and the environment to change on a seasonal basis. With this study, we had the unique opportunity to analyse a large amount of porpoise sighting data, collected at a very high spatial and temporal resolution during 3 seasons of 4 consecutive study years using line-transect aerial surveys.

Here, we aimed to identify possible physiographic, hydrographical and biological factors that could serve as environmental cues for harbour porpoises to locate feeding areas. Using identified predictors, our aim was to develop robust seasonal habitat prediction models and further validate model predictions using an independent data set. Finally, we aimed to estimate modelbased seasonal abundances for the 3 SACs in the German Bight in order to inform management frameworks to determine safe limits of anthropogenic impacts.

\section{MATERIALS AND METHODS}

Study area. Our study area is situated in the southeastern North Sea. We collected data on harbour porpoises mainly in the German Exclusive Economic Zone (EEZ), whereas data on environmental properties were also compiled for an adjacent area (Fig. 1), as we aimed to predict harbour porpoise summer density on a regional scale. The bathymetry of the German Bight is characterised by (1) the shallow Wadden Sea $(<10 \mathrm{~m})$ with the estuaries of the rivers Ems, Weser, Elbe and Eider, (2) the deep wedge-shaped post-glacial Elbe River valley $(>30 \mathrm{~m})$, that extends from the Elbe estuary to the northwest and passes the Dogger Bank on the eastern side of Tail End, and (3) the central part of the German Bight area, with depths between 40 and $60 \mathrm{~m}$ (Becker et al. 1992) (Fig. 1). The residual current runs in a counter-clockwise direction and transports the water masses of the inner German Bight in a northerly direction (Becker et al. 1992). The hydrographical situation is complex and is characterised by tidal currents and substantial gradients in salinity that are formed by the encounter of different water bodies (Krause et al. 1986).

Harbour porpoise data. High-quality data on harbour porpoise distribution were available from dedicated aerial surveys that we conducted year-round in the German EEZ and the 12 nautical mile (n mile) zone between May 2002 and November 2005 using standard line-transect methodology (Buckland et al. 2001). The study area $\left(41045 \mathrm{~km}^{2}\right)$ was divided into 4 geographic strata in which we designed a systematic set of 72 parallel transects with a total transect length of $4842 \mathrm{~km}$. One survey stratum could usually be surveyed within $1 \mathrm{~d}$ (5 to $9 \mathrm{~h}$ of flying). Transects were placed to provide equal coverage probability within each block (Gilles et al. 2009). Aerial surveys were flown at 100 knots $\left(185 \mathrm{~km} \mathrm{~h}^{-1}\right)$ at an altitude of $600 \mathrm{ft}$ (183 m) in a Partenavia P68, a twin-engine, high-wing aircraft equipped with 2 bubble windows to allow scanning directly underneath the plane. The survey team consisted of 2 observers, 1 data recorder (navigator) and the pilot. Surveys were only conducted during Beaufort sea states of 0 to $<3$ and with visibilities $>5 \mathrm{~km}$. Estimation of effective strip widths and $g(0)$, following the racetrack data collection method (Hiby \& Lovell 1998, Hiby 1999), allowed for precise effort correction and accounted for missed animals and sighting conditions (Scheidat et al. 2008). Detailed field and analyses protocols are described in Gilles et al. (2009) and Scheidat et al. (2008).

We completed 76 survey days, resulting in a total effort of $38720 \mathrm{~km}$ and 3088 sightings (Table 1). Data of the 4 study years were pooled by season as we detected no differences in inter-annual porpoise distribution over the study period (Gilles et al. 2009). We defined seasons as spring (March, April, May), summer (June, July, August) and autumn (September, October, November). The effort was comparable between the 3 seasons (Table 1). The winter months (December, January, February) were excluded due to low search effort. 
Table 1. Phocoena phocoena. Sighting data. Results of the line-transect aerial survey in the German Exclusive Economic Zone and 12 nautical mile zone. Effort summary per season and main survey results in good and moderate sighting conditions are shown. Each season was pooled over the years 2002 to 2005

\begin{tabular}{|lcccc|}
\hline & $\begin{array}{c}\text { Flight } \\
\text { days }\end{array}$ & $\begin{array}{c}\text { Track line } \\
\text { length (km) }\end{array}$ & $\begin{array}{c}\text { No. of } \\
\text { groups }\end{array}$ & $\begin{array}{c}\text { No. of } \\
\text { individuals }\end{array}$ \\
\hline Spring & 19 & 10081 & 1234 & 1470 \\
Summer & 32 & 15511 & 1462 & 1900 \\
Autumn & 25 & 13128 & 392 & 517 \\
Total & 76 & 38720 & 3088 & 3887 \\
\hline
\end{tabular}

All spatial analyses were conducted at a resolution of $10 \times 10 \mathrm{~km}$ in ArcGIS 9.2 (ESRI). Porpoise sighting data were extracted for each $10 \mathrm{~km}$ segment of oneffort transect. We selected this resolution to ensure that sighting conditions and geographic location did not change appreciably within this sampling unit (Hedley \& Buckland 2004). We derived an estimate of porpoise density corrected for the detection probability (see Gilles et al. 2009) and used these estimates as our response variable. Additionally, the survey effort was included in the model formula as a weighting factor to prevent potential biases resulting from over- or undersampling sub-regions within each block.

Testing for seasonal differences. We carried out an exploratory analysis to determine potential significant seasonal shifts in porpoise distribution. We used a generalised additive model (GAM) to model porpoise density based on latitude and longitude following Wood (2006, p. 239) to test for the effect of season. At first, assuming no difference in spatial distribution throughout the year, all data were pooled. A second model was applied assuming differences in spatial distribution patterns caused by season (using by variables in 'mgcv
1.4-1.1' in R v.2.8.1; Wood 2008). Both models were then compared by their residual deviance (using the anova.gam function). If there was a significant difference between both models, we concluded that there was evidence against symmetry and that this effect was due to the factor 'season'. This approach was carried out for all seasons. Results indicated significant differences between all of the 3 seasons (all $\mathrm{p}<0.001$ ). Consequently, we developed 3 distinct seasonal habitat prediction models.

Explanatory variables. The explanatory variables were selected based on a priori knowledge of factors known to indirectly determine harbour porpoise distribution by influencing patterns in prey occurrence. As it was not possible to collect in situ oceanographic data during the aerial surveys, we compiled spatially referenced oceanographic and remotely sensed data from different oceanographic databases. All data sets were processed in ArcGIS 9.2 to generate corresponding gridded environmental data at the selected resolution of $10 \times 10 \mathrm{~km}$.

We used a combination of static and dynamic predictors to fit the models, as listed in Table 2 and discussed in detail in the following.

Static predictors: Distance to shore (DIST) was calculated in ArcGIS as the shortest distance between the midpoint of each grid cell and the closest point on the coastline. Water depth (DEPTH) data were obtained from a digital bathymetric map set with a spatial resolution of $617 \mathrm{~m}$. As DIST and DEPTH are correlated $\left(R^{2}=0.8, p<0.05\right)$, these 2 variables were included as an interaction term (DIST,DEPTH) in all models. We hypothesised that this interaction term could be important to capture the complex topography of the German Bight, where there are a number of offshore shallows (e.g. Amrum and Dogger Banks). Bottom slope (SL) was derived from the depth data by using the Spatial Analyst extension (Surface Analyst -

Table 2. Overview of explanatory variables used for harbour porpoise habitat modelling. Average values for predictors within the Exclusive Economic Zone and 12 nautical mile zone are shown. Abbreviations as used throughout the text. DIST,DEPTH was included as an interaction term

\begin{tabular}{|c|c|c|c|c|c|c|}
\hline $\begin{array}{l}\text { Explanatory } \\
\text { variable }\end{array}$ & Abbreviation & Unit & $\begin{array}{l}\text { Predictor } \\
\text { category }\end{array}$ & $\begin{array}{l}\text { Spring mean } \\
(\text { median }) \pm S D\end{array}$ & $\begin{array}{l}\text { Summer mean } \\
(\text { median }) \pm S D\end{array}$ & $\begin{array}{l}\text { Autumn mean } \\
(\text { median }) \pm \mathrm{SD}\end{array}$ \\
\hline Distance to shore & DIST & $\mathrm{km}$ & Static & $81.4(65.6) \pm 71.0$ & $81.4(65.6) \pm 71.0$ & $81.4(65.6) \pm 71.0$ \\
\hline Water depth & DEPTH & $\mathrm{m}$ & Static & $29.3(33.0) \pm 13.6$ & $29.3(33.0) \pm 13.6$ & $29.3(33.0) \pm 13.6$ \\
\hline Slope & SL & $\circ$ & Static & $0.05(0.03) \pm 0.05$ & $0.05(0.03) \pm 0.05$ & $0.05(0.03) \pm 0.05$ \\
\hline Sea surface salinity & SAL & PSU & Dynamic & $31.9(33.3) \pm 3.5$ & $32.7(33.4) \pm 2.1$ & $32.2(32.5) \pm 2.1$ \\
\hline Sea surface temperature & SST & ${ }^{\circ} \mathrm{C}$ & Dynamic & $9.2(8.9) \pm 0.8$ & $17.3(17.2) \pm 0.9$ & $15.1(15.2) \pm 0.6$ \\
\hline Residual current & CURR & $\mathrm{m} \mathrm{s}^{-1}$ & Dynamic & $0.07(0.07) \pm 0.02$ & $0.06(0.06) \pm 0.01$ & $0.09(0.09) \pm 0.02$ \\
\hline Sea surface chlorophyll & $\mathrm{CHL}$ & $\mathrm{mg} \mathrm{m}^{-3}$ & Dynamic & $5.4(4.4) \pm 3.6$ & $6.1(5.1) \pm 4.5$ & $4.3(3.0) \pm 3.8$ \\
\hline Chlorophyll range & CHL_r & $\mathrm{mg} \mathrm{m}^{-3}$ & Dynamic & $9.4(7.0) \pm 8.0$ & $10.2(8.4) \pm 8.0$ & $11.2(9.2) \pm 8.6$ \\
\hline Silicate & SI & $\mu \mathrm{mol} \mathrm{l} \mathrm{l}^{-1}$ & Dynamic & $8.8(6.4) \pm 6.3$ & $1.7(1.1) \pm 1.3$ & $5.5(3.7) \pm 4.1$ \\
\hline Nitrogen & NI & $\mu \mathrm{mol} \mathrm{l} \mathrm{l}^{-1}$ & Dynamic & $18.7(12.7) \pm 15.1$ & $25.4(20.8) \pm 15.6$ & $25.9(16.5) \pm 21.8$ \\
\hline
\end{tabular}


slope) in ArcGIS. Although derived from the bathymetry, the slope at a particular location is independent of its depth (here: $\mathrm{R}^{2}=-0.5$ ).

Dynamic predictors: We compiled data on dynamic predictors for spring, summer and autumn across all 4 study years in order to capture the range of seasonal and inter-annual environmental variability. We strove to match each survey day with corresponding data for each dynamic predictor at the highest available resolution so as to capture the environmental situation for each flight day as accurately as possible. Variables were subsequently pooled for each season and averaged across all years.

Sea surface temperature (SST) data were available at a weekly resolution and were provided by the German Federal Maritime and Hydrographic Agency (BSH) and derived from satellite data (Becker \& Pauly 1996). In order to derive mean seasonal values, we processed a total of 16, 21 and 21 weekly composites for spring, summer and autumn, respectively.

Data on residual currents (CURR) were computed by the operational circulation model 'BSHcmod' and provided by the BSH with a spatial resolution of $1 \mathrm{n}$ mile on a daily basis. The so-called residual currents define the net transport of the water mass, i.e., the influence of the tidal currents is eliminated by suitable averaging, here over 2 tidal periods (Dick et al. 2001).

Surface chlorophyll concentration (CHL) was obtained from the multispectral sensor Medium Resolution Imaging Spectrometer (MERIS) onboard the European Space Agency (ESA)'s ENVISAT satellite (Doerffer et al. 1999). We analysed satellite images using the BEAM software (www.brockmann-consult. de/beam). Mean values of surface chlorophyll concentration were extracted in ArcGIS from GeoTIFF files produced in BEAM by selecting the suitable spatial and band subset (algal_2, chlorophyll absorption). As a proxy for fronts or upwelling zones, which are often characterised by chlorophyll anomalies, we subsequently derived 'chlorophyll range' (CHL_r) from the chlorophyll data; representing the difference between the maximum and minimum pixel value within our $10 \times 10 \mathrm{~km}$ grid cells .

We processed data on sea surface salinity (SAL) and selected nutrients (silicic acid, $\mathrm{SI}_{i}$ and total nitrogen, NI) from in situ measurements taken at oceanographic stations provided by the International Council for the Exploration of the Seas (ICES) and the German Oceanographic Data Centre. We used these point coverages of salinity and nutrient concentrations to create interpolated raster surfaces across the study area. For interpolation we used the ordinary kriging function in ArcGIS (Geostatistical Analyst). However, we were only able to calculate seasonal values of nutrient concentration for spring and autumn 2004 and for summer 2002, as the sampling coverage was insufficient in the other years to allow a robust interpolation by season.

Model selection. Using the GAM setup of 'mgcv 1.41.1' in R v.2.8.1 (R Development Core Team 2008), we modelled the estimated probability of porpoise density at any site as an additive function of the selected environmental predictors using a logarithmic link and a quasi-likelihood error distribution to account for overdispersion in the data.

Model selection by season was based on identifying which predictors had significant effects by using backward (stepwise) selection (Redfern et al. 2006) and by stepwise comparing models using ANOVA. The 'mgcv' package uses an automated generalised cross-validation for model fitting (GCV score; Wood 2008). We set the significance level to $\alpha=0.1$ in order not to exclude important predictors, as the study area is very heterogeneous. However, this only became an issue in spring when the model significantly improved when including CHL (Table 3), as shown by the ANOVA.

Model error for the best-fit models was determined as the sum of squared residuals. However, model selection may have been biased due to (1) residual spatial autocorrelation (SACor) violating the assumption of independence of observations (Legendre 1993) and (2) multicollinearity (Zuur et al. 2010). To address possible bias (1), we plotted a correlogram of the residuals and visually inspected for signs of SACor (Keitt et al. 2002). In addition, we compared GAM performance with a generalised additive mixed model (GAMM; e.g. Wood 2008), as this allows modelling of non-linear relationships while explicitly taking SACor into account. The SACor structure we used in the mixed effect model (function gamm in 'mgcv') has an exponential structure and is implemented by the 'corExp' functions of the 'nlme' package in R (Pinheiro \& Bates 2000). To deal with bias (2), we determined the variance inflation factors (VIF) and set a stringent threshold of VIF = 3 as suggested by Zuur et al. (2010).

Assessment of model performance and validation. To assess model performance, we compared observed porpoise densities with predicted density surfaces. The spatial distribution of the response residuals by grid cell was also mapped in order to identify areas where the model over- or underestimated density (i.e. residuals were negative or positive, respectively).

Subdividing our study area into 9 spatial subsets of equal size, we followed standard k-fold cross-validation (Wood 2006, Schröder 2008) to validate the predictive accuracies of the resulting best-fit models using withheld subsets as test data by calculating the root mean square error of prediction (RMSEP; Redfern et al. 2008). 
Table 3. Best-fit model. F-values, significance test p-values and estimated degrees of freedom (edf) are given for the explanatory variables (for abbreviations, see Table 2). The adjusted $R^{2}$, deviance explained (\%) and model error (sum of squared residuals) are also shown. Terms that were not significant (NS, p > 0.1) were dropped from the model. MC: not included due to multicollinearity. GAM: generalised additive model

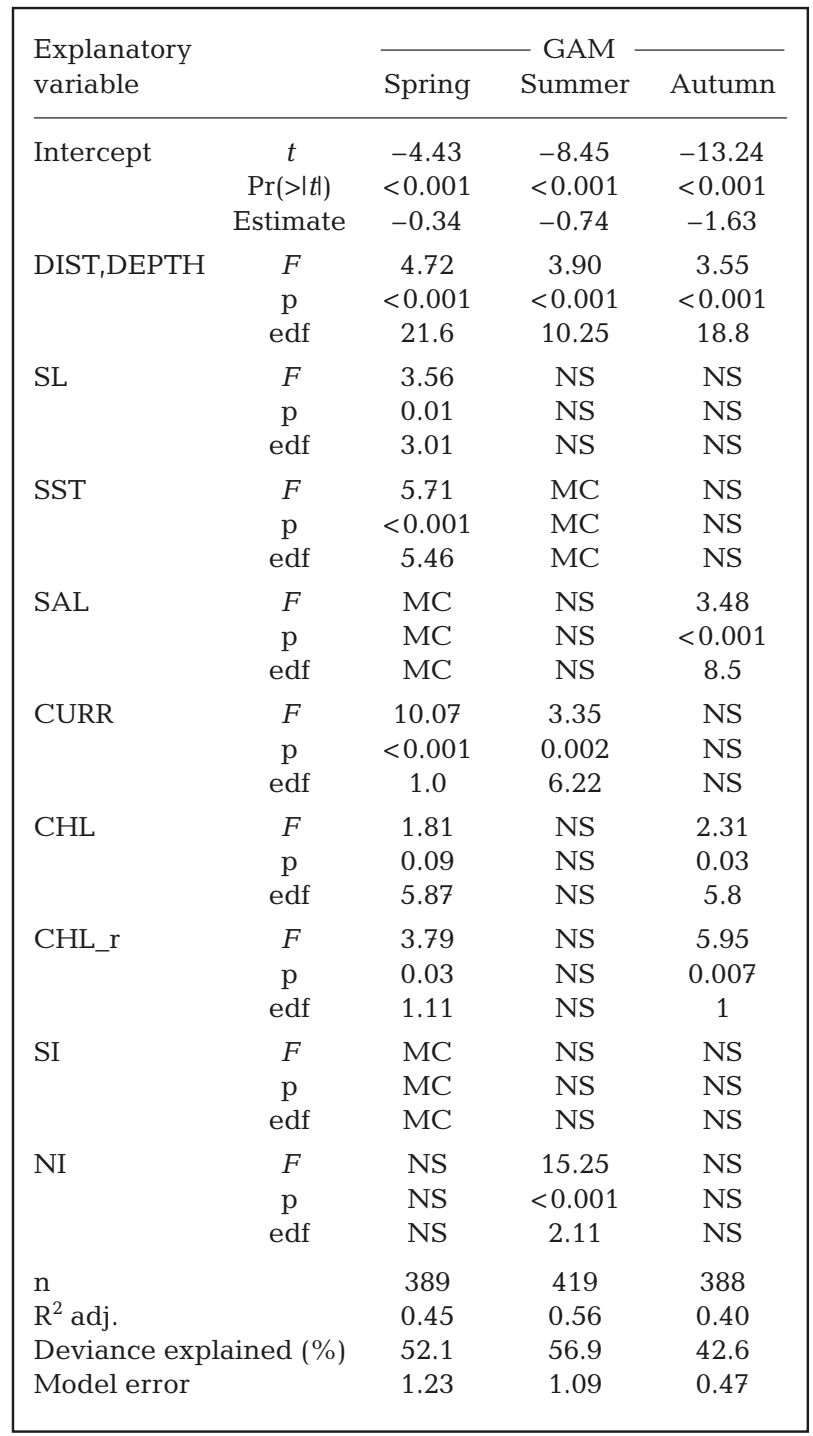

Here, we carried out both internal and external validations based on an enlarged study area (white box in Fig. 1), which encompassed a sufficiently large proportion of the area covered by the SCANSII survey providing our independent data (see below). We performed internal validation of each season by using subsets of the original data and the external validation by using independent data to validate the summer model. The independent data were collected during the SCANS-II survey, which estimated small cetacean abundance in the North Sea and European Atlantic continental shelf waters in July 2005 (SCANS-II 2008). We used data of survey blocks that overlapped with our study area (i.e. blocks H, L, U, V and Y; see SCANS-II 2008).

Estimation of abundance and variance. The final selected models were parameterised in all grid cells to generate a density surface over the whole study area. Abundance of animals in the SACs was predicted by integrating under the density surface. The variance of the abundance estimates was generated using nonparametric bootstrap methods (10 000 replicates; Efron 1990), where the models were re-fitted for each bootstrap iteration.

\section{RESULTS}

\section{Model selection}

In general, selected predictors varied between the 3 seasons. The summer model explained the highest deviance, followed by spring and autumn (Table 3). The interaction (DIST,DEPTH) was the predictor most often selected in all models, followed by residual current (CURR) and chlorophyll concentration (CHL). As single factors, nitrogen (NI) and CURR each explained the most deviance, which is indicated by the high associated F-value (Table 3). As a measure of goodness of fit, we analysed diagnostic plots and spatial structure of residuals that indicated no autocorrelation of residuals. Further, the comparison between GAM and GAMM outputs indicated that model performance and predictions were very similar. For all 3 seasons, scatter plots of GAM versus GAMM residuals showed unskewed distributions of residuals, indicating similar predictive ability of both models. Similarly, the mean error and the spatial distribution of the residuals were comparable during all seasons for both approaches, although the GAMM in fact performed worse than the less complex GAM.

\section{Observed and predicted distribution}

In spring, observed harbour porpoise distribution was highly heterogeneous (Fig. 2a). Porpoise density was highest in the north-east around the Sylt Outer Reef (SOR, see Fig. 1) and about $60 \mathrm{~km}$ offshore of the East Frisian Islands, in an area called Borkum Reef Ground (BRG, see Fig. 1). Other high density areas were found at the Dogger Tail End (Fig. 2a).

The modelled response surface (Fig. 2b) showed a good fit of the observed density distribution and captured the 2 hot spots in SOR and BRG very well. The smaller hot spot at the edge of the Dogger Bank was also 


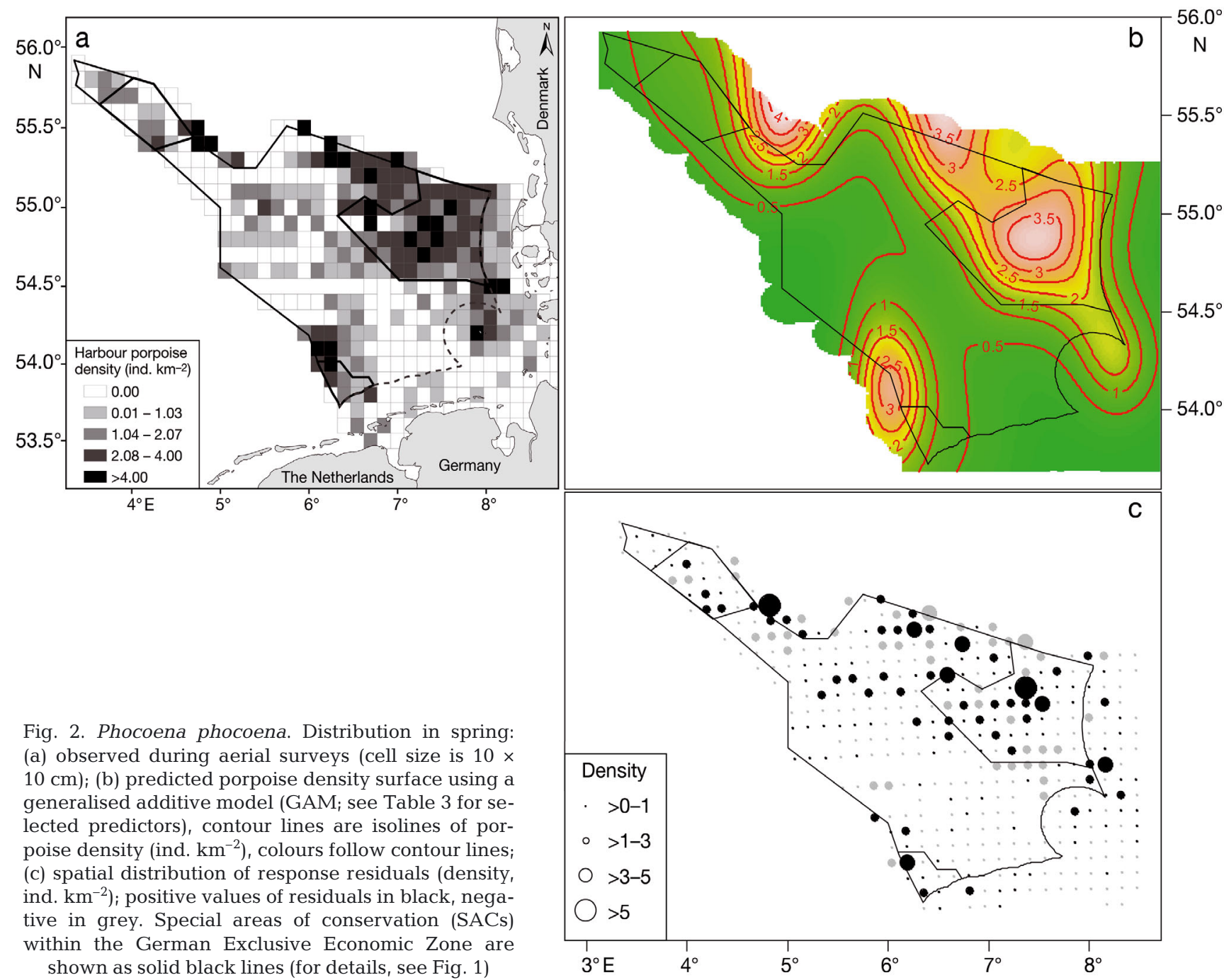

predicted successfully. The model predicted increasing porpoise density, when moving from the island of Heligoland north towards SOR and further north-west.

Maximum porpoise densities within our study area were observed in the summer and were accompanied by a substantial northward shift, resulting in a decrease of densities in the southern German Bight and an increase in the North (Fig. 3a). The response surface showed a very good fit with the observed spatial pattern (Fig. 3b). The aerial surveys in autumn revealed that porpoises were more evenly dispersed throughout the study area and that they occurred at lower densities in comparison to the other seasons (Fig. 4a). This pattern was captured well by the model. The predicted density surface showed 2 focal areas, one again around the reef structure of the SOR and another at the Dogger Tail End (Fig. 4b).

The spatial distribution of response residuals showed that the GAM underestimated density in the north-east and along the northern frontier of the EEZ in spring and summer (Figs. 2c \& 3c), whereas in autumn residuals showed low values and no particular area with extreme under- or overestimation (Fig. 4c).

\section{Model validation}

Internal and external cross-validation also provided support for a good fit for all 3 models, as indicated by low RMSEPs. RMSEPs based on internal validation were very similar between spring $($ RMSEP $=1.79)$ and summer (RMSEP $=1.51$ ) and lowest for autumn (RMSEP $=0.57)$. As RMSEPs are not standardised, this has to be seen in the context of densities being lowest in autumn. The external validation with the independent data set SCANS-II focused on the transferability and generalisability of the summer model and resulted 


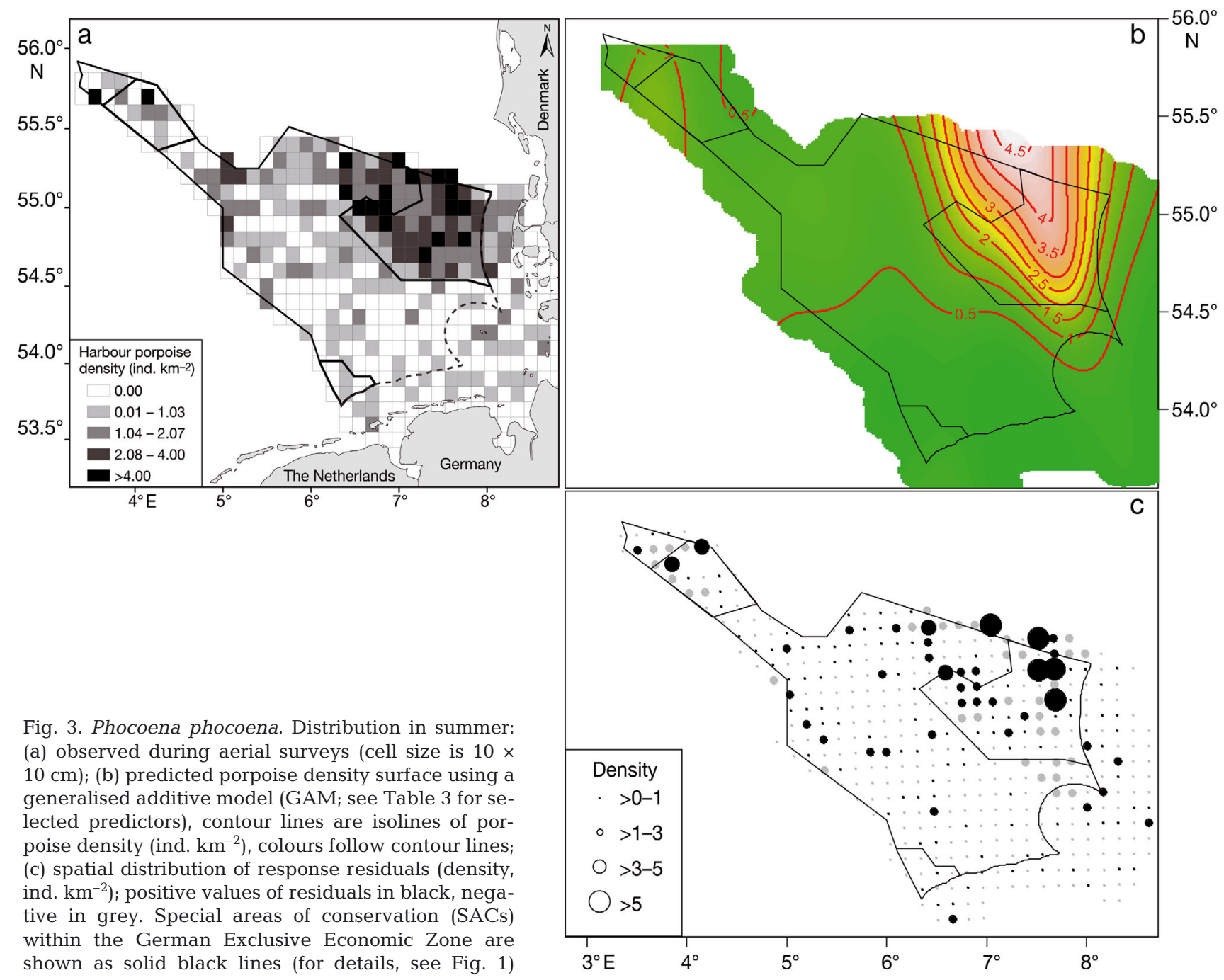

in a positive validation (RMSEP $=1.21$ ). As a consequence, we used the GAM best-fit model, based on the local summer data, to predict porpoise density for a more regional scale as supported by the SCANS-II validation (Fig. 5). The results showed that the summer hot spot in the north-eastern German Bight was predicted to extend far into Danish waters. Additional high density areas were predicted offshore the West Frisian Islands in the Netherlands, near the Eastern Channel and on the Dogger Bank.

\section{Model-based abundance estimates}

The seasonal abundance estimates for the area of the 3 SACs show highest estimates for SOR and DB in summer and for BRG in spring (Table 4). In general, confidence intervals are narrow and coefficients of variation are of low value.

\section{DISCUSSION}

As scientists advising conservation agencies and managers, we are frequently asked to provide information on distribution and abundance for specific areas. Such requests are often the basis for marine spatial planning and the definition of anthropogenic impact zones or for the establishment of significance thresholds for designated marine protected areas. The size of such areas of interest often means that this demand cannot be met by dedicated surveys alone, since these can only provide estimates for predefined survey strata. Instead, density surfaces are needed; these require modelling and, in turn, an ultimate understanding of the environmental factors which influence seasonal distribution in order to predict changes. This is the first study to investigate Phocoena phocoena distribution and density throughout the year as a function of the complex and dynamic German Bight envi- 


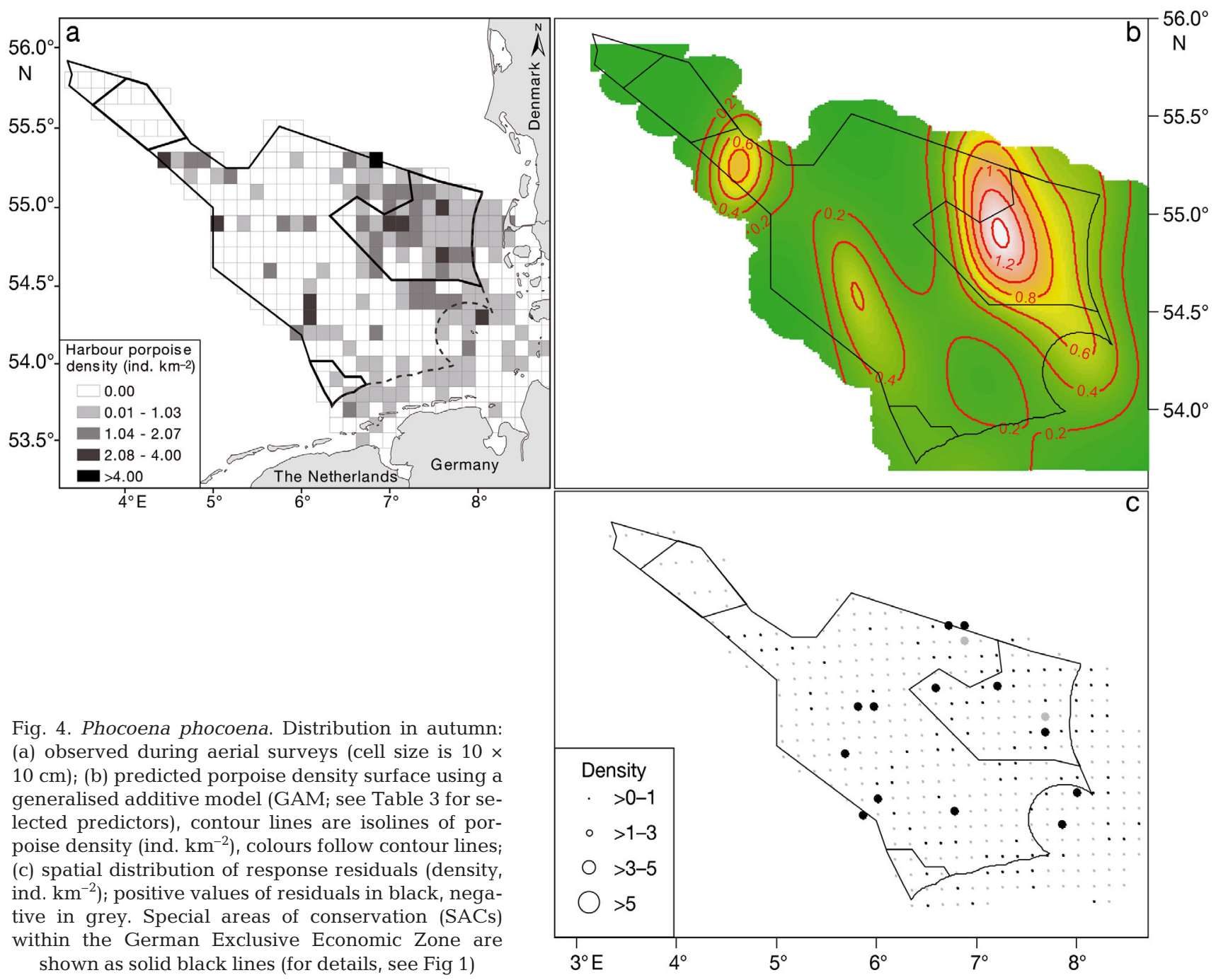

ronment. We were able to develop models generating good predictions. By including a range of static as well as dynamic habitat predictors, we were able to increase the resolution of the density prediction beyond what would have been possible using stratified linetransect analysis only and were thus able to estimate abundance for the 3 SACs. Extensive validation of our models provided support for the robustness and precision of the predicted patterns of harbour porpoise density in the south-eastern North Sea. However, it is clear that these models cannot be used to make inferences about all parts of the North Sea, and predictions outside the study area should not be over-interpreted.

\section{Seasonal focal areas}

Our models suggest significant differences in the seasonal distribution patterns of harbour porpoises and indicate that animals aggregate in distinct hot spots within their seasonal range. We showed the importance of taking seasonal variations into account, as the core area around BRG, for example, would have been neglected if only surveyed in summer. The SOR represents the most important focal region throughout the year. It is also an important breeding area and holds about $80 \%$ of all detected mother-calf pairs in summer (Gilles et al. 2009). BRG and DB are highly frequented in spring and autumn. The area between SOR and BRG could thus represent an important migratory corridor. However, data on individual porpoise movements (e.g. based on satellite telemetry) are not available for this area. Future investigations should therefore investigate habitat use, especially as this is an area where the largest number of OWFs are planned. By expanding predictions for summer to a more regional scale, we were able to show that the hot spot in SOR extended far into Danish waters. From a scientific per- 


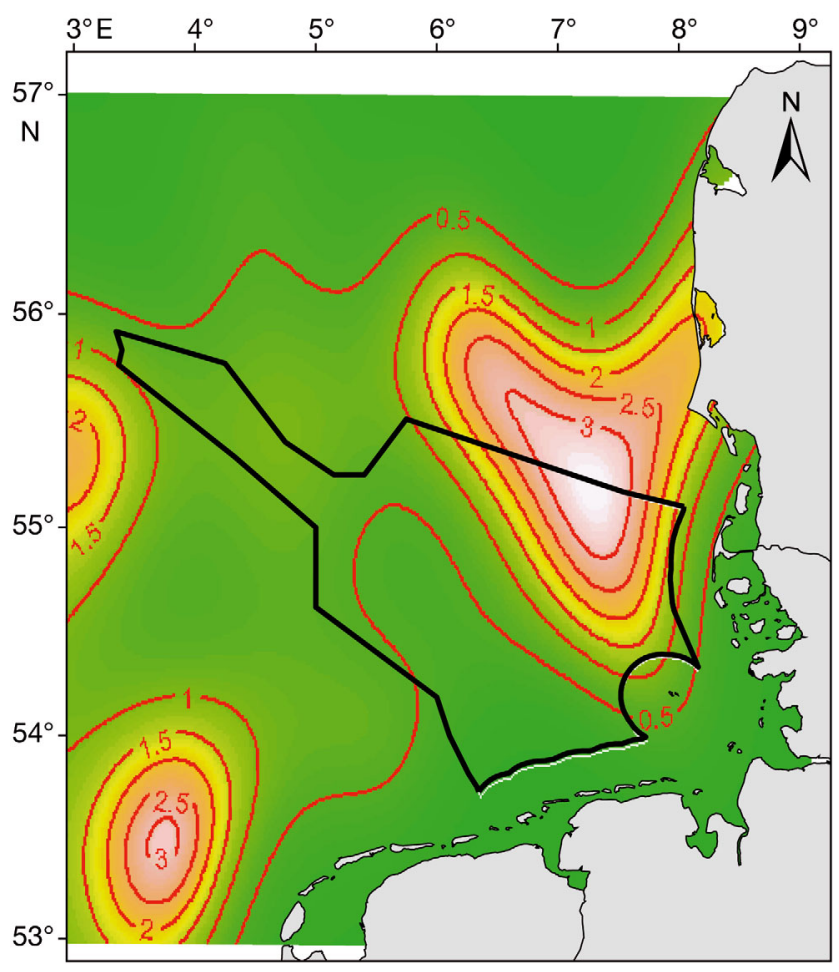

Fig. 5. Phocoena phocoena. Predicted density (ind. $\mathrm{km}^{-2}$ ) surface in summer by selected predictors using a generalised additive model (GAM; see Table 3 for selected predictors). Contour lines are isolines of porpoise density; colours follow contour lines. Black contour: German Exclusive Economic Zone. Model validation with SCANS-II data

spective, transnational management appears to be the most rational approach to achieve long-term conservation. We therefore suggest that Denmark adjoin their SACs in the North Sea to the borders of the German SACs as suggested by Teilmann et al. (2008). The same applies to the Netherlands and the UK, as the SACs BRG and DB are clearly too small to be of value for the conservation of the mobile harbour porpoises.

Table 4. Phocoena phocoena. Estimates of abundance $(\mathrm{N})$ and density $\left(\mathrm{D}\right.$; ind. $\left.\mathrm{km}^{-2}\right)$ from model-based density surface modelling for each special area of conservation (SAC) with the coefficient of variation (CV). 95\% confidence intervals are in parentheses

\begin{tabular}{|llccc|}
\hline SAC (area) & Season & $\mathrm{N}$ & $\mathrm{D}$ & $\mathrm{CV}$ \\
\hline Sylt Outer Reef & Spring & $12125(11153-13147)$ & $2.28(2.10-2.47)$ & 0.04 \\
$\left(5314 \mathrm{~km}^{2}\right)$ & Summer & $12504(11170-13910)$ & $2.35(2.10-2.62)$ & 0.06 \\
& Autumn & $3569(3064-4099)$ & $0.67(0.58-0.77)$ & 0.07 \\
Borkum Reef Ground & Spring & $1026(605-1520)$ & $1.64(0.97-2.43)$ & 0.23 \\
$\left(625 \mathrm{~km}^{2}\right)$ & Summer & $131(93-173)$ & $0.21(0.15-0.28)$ & 0.16 \\
& Autumn & $128(78-196)$ & $0.21(0.13-0.31)$ & 0.24 \\
Dogger Bank & Spring & $1639(1212-2205)$ & $1.01(0.75-1.36)$ & 0.16 \\
$\left(1624 \mathrm{~km}^{2}\right)$ & Summer & $1504(1291-1734)$ & $0.93(0.79-1.07)$ & 0.08 \\
& Autumn & $120(67-185)$ & $0.07(0.04-0.11)$ & 0.25 \\
\hline
\end{tabular}

\section{Factors affecting harbour porpoise distribution}

Given the complexity of marine trophic interactions, it is difficult to identify specific individual predictors that directly affect prey aggregations or otherwise determine the habitat use of a predator. Our findings suggest that a range of different dynamic and static parameters play important roles, since all best-fit models included at least 1 type of physiographic as well as hydrographical and biological predictors.

Residual currents appeared to be important in determining porpoise distributions during most seasons. Our results support other studies which also found a preference of harbour porpoises for areas associated with strong currents, such as islands and headland wakes (Johnston et al. 2005) or tide race areas (Pierpoint 2008) where prey often aggregate or are aggregated.

Similarly, harbour porpoises in our study area appeared to aggregate along steep gradients of chlorophyll concentration, indicative of localised patches of primary production and fronts (Mann \& Lazier 2006), which are known to increase food availability for top predators (e.g. Ballance et al. 2006). This has been shown for seabirds in the German Bight (Skov \& Prins 2001, Markones 2007) and for harbour porpoises in the Bay of Fundy (Johnston et al. 2005). Fronts are dynamic oceanographic features and are of great ecological relevance in the German Bight (Becker et al. 1999). A convergence zone near the East Frisian coast, also known as the 'cold belt' (Krause et al. 1986), can under certain conditions cover the whole southern German Bight in its east-west extension (Otto et al. 1990) and could be the explanation for the hotspot at BRG during spring.

Estuarine fronts, associated with fluctuations in salinity and nutrients, represent more permanent oceanographic features which exist throughout the year (Krause et al. 1986). The importance of surface salinity in the autumn model may be indicative of the role that the large estuarine fronts in the eastern German Bight play as foraging sites for harbour porpoises.

Similar to other studies (Pierpoint 2008), we also found a preference of porpoises to forage in areas of steep bottom topography, such as the topographically dynamic, postglacial Elbe River valley which is basically a submarine canyon acting as an important feature for prey aggregation. For instance, the extension of our predicted hotspot around SOR towards Heligoland coincides with an area of the Elbe River valley near Heligoland where 
ephemeral upwelling occurs when easterly winds prevail (Krause et al. 1986).

In addition to salinity and temperature, nutrient data are a valuable tool to differentiate water masses and provide information on the recent state of biogeochemical turnover processes (Ehrich et al. 2007). In our summer model, total nitrogen concentration was the most influential predictor, and porpoise densities were predicted to be higher in areas where nitrogen concentration was low. As the depletion of nutrients such as nitrogen may be indicative of preceding phytoplankton blooms, low nitrogen levels suggest the onset of secondary production. Porpoise aggregation in such areas can be expected to occur with a certain time lag to allow for sufficient time for zooplankton abundance to rise, fish to locate the area and top predators to arrive.

\section{Model-based abundance estimates}

Predictive cetacean-habitat modelling is very useful in that the incorporation of oceanographic variability can improve conventional abundance estimates by reducing the variance (Forney 2000, Gómez de Segura et al. 2007) as also shown in the present study. In comparison, conventional line-transect estimates for the survey block including SOR resulted in 2.41 ind. $\mathrm{km}^{-2}$ (95\% CI: $1.37-4.75 ; \mathrm{CV}=0.33$ ) in summer (Gilles et al. 2009). Thus, model-based estimates provide a higher potential to detect significant changes in local abundances. It is clearly of advantage that spatial models allow abundance estimation in any subset of the study area, but the robustness of such estimates depends on the appropriateness and the validation of the fitted model. It must be applied with considerable caution, particularly if the sub-area is small relative to the modelled area (Hammond 2010). Unfortunately, there is not yet a rule of thumb to determine a 'small' area. Future work should consider this issue in more detail. However, we are aware that the SAC BRG in particular is small in comparison to the hot spot predicted in spring, and this should be kept in mind when using these estimates in a management context.

\section{CONCLUSION}

Our models provide important new information in understanding the determinants of harbour porpoise seasonal habitat in the North Sea. Further modelling exercises could include food competitors (such as harbour seals), concrete disturbance factors (e.g. anthropogenic noise) or effects of climate change (e.g. increase in water temperature or change in currents).
The study clearly showed that the influence of predictors varied between seasons, highlighting the importance of taking seasonal variations into account in any marine spatial planning exercise. The delimitation of SACs in our area proved to be, in part, a good fit concerning core areas for Phocoena phocoena. The full impact of OWFs in terms of the user-environment conflict cannot be quantified until further farms have been built; however, our models could then be used as valuable tools to help managers address concerns about the potential impact from human activities.

Acknowledgements. Aerial surveys were financed by the German Federal Ministry for the Environment, Nature Conservation and Nuclear Safety (BMU; MINOS and MINOSplus, FKZ 0327520, 0329946B), Ministry of Food, Agriculture and Consumer Protection (BMELV; 514-33.29/03HS059) and the Federal Agency for Nature Conservation (BfN; EMSON, FKZ 80285260). We thank all pilots, observers and navigators. Thanks also to F. Colijn and 2 anonymous reviewers for valuable comments on the manuscript. We thank the German Federal Maritime and Hydrographic Agency (BSH), the International Council for the Exploration of the Seas (ICES) and the GKSS Research Centre, Department of Operational Systems, for providing the various data sets. We are grateful to G. Bruss for assistance with data on residual currents. Thanks to P. Hammond and all the people and institutions involved in SCANS-II.

\section{LITERATURE CITED}

Ballance LT, Pitman RL, Fiedler PC (2006) Oceanographic influences on seabirds and cetaceans of the eastern tropical Pacific: a review. Prog Oceanogr 69:360-390

Becker GA, Pauly M (1996) Sea surface temperature changes in the North Sea and their causes. ICES J Mar Sci 53:887898

Becker GA, Dick S, Dippner J (1992) Hydrography of the German Bight. Mar Ecol Prog Ser 91:9-18

Becker GA, Giese $H$, Isert $K$, König P, Langenberg $H$, Pohlmann T, Schrum C (1999) Mesoscale structures, fluxes and water mass variability in the German Bight as exemplified in the KUSTOS-experiments and numerical models. Ocean Dyn 51:155-179

Beineke A, Siebert U, Stott J, Müller G, Baumgärtner W (2007) Phenotypical characterization of changes in thymus and spleen associated with lymphoid depletion in freeranging harbor porpoises (Phocoena phocoena). Vet Immunol Immunopathol 117:254-265

Buckland ST, Anderson DR, Burnham KP, Laake JL, Borchers DL, Thomas L (2001) Introduction to distance sampling. Estimating abundance of biological populations. Oxford University Press, New York, NY

> Das K, Vossen A, Tolley K, Vikingsson GA and others (2006) Interfollicular fibrosis in the thyroid of the harbour porpoise: an endocrine disruption? Arch Environ Contam Toxicol 51:720-729

Dick S, Kleine E, Müller-Navarra S, Klein H, Komo H (2001) The operational circulation model of BSH (BSHcmod) model description and validation. Ber BSH no. 29. Federal Maritime and Hydrographic Agency (BSH), Hamburg

> Doerffer R, Sorensen K, Aiken J (1999) MERIS potential for coastal zone applications. Int J Remote Sens 20:1809-1818 
Efron B (1990) More efficient bootstrap computations. J Am Stat Assoc 85:79-89

Ehrich S, Adlerstein A, Brockmann U, Floeter U and others (2007) 20 years of German small-scale bottom trawl survey (GSBTS): a review. Senckenb Marit 37:13-82

Embling CB, Gillibrand PA, Gordon J, Shrimpton J, Stevick PT, Hammond PS (2010) Using habitat models to identify suitable sites for marine protected areas for harbour porpoises (Phocoena phocoena). Biol Conserv 143:267-279

Forney KA (2000) Environmental models of cetacean abundance: reducing uncertainty in population trends. Conserv Biol 14:1271-1286

Gill AB (2005) Offshore renewable energy: ecological implications of generating electricity in the coastal zone. J Appl Ecol 42:605-615

Gilles A (2009) Characterisation of harbour porpoise (Phocoena phocoena) habitat in German waters. PhD dissertation, University of Kiel

Gilles A, Scheidat M, Siebert U (2009) Seasonal distribution of harbour porpoises and possible interference of offshore wind farms in the German North Sea. Mar Ecol Prog Ser 383:295-307

Gómez de Segura A, Hammond PS, Cañadas A, Raga JA (2007) Comparing cetacean abundance estimates derived from spatial models and design-based line transect methods. Mar Ecol Prog Ser 329:289-299

Hammond PS (2010) Estimating the abundance of marine mammals. In: Boyd IL, Bowen WD, Iverson SJ (eds) Marine mammal ecology and conservation. Oxford University Press, Oxford, p 42-67

Hammond PS, Berggren P, Benke H, Borchers DL and others (2002) Abundance of harbour porpoises and other cetaceans in the North Sea and adjacent waters. J Appl Ecol 39:361-376

Hedley SL, Buckland ST (2004) Spatial models for line transect sampling. J Agric Biol Environ Stat 9:181-199

Hiby AR (1999) The objective identification of duplicate sightings in aerial survey for porpoise. In: Garner GW, Amstrup SC, Laake JL, Manly BFJ, McDonald LL, Robertson DG (eds) Marine mammal survey and assessment methods. Balkema, Rotterdam, p 179-189

Hiby AR, Lovell P (1998) Using aircraft in tandem formation to estimate abundance of harbour porpoises. Biometrics 54: 1280-1289

Johnston DW, Westgate AJ, Read AJ (2005) Effects of finescale oceanographic features on the distribution and movements of harbour porpoises Phocoena phocoena in the Bay of Fundy. Mar Ecol Prog Ser 295:279-293

Keitt T, Bjornstadt O, Dixon P, Citron-Pousty S (2002) Accounting for spatial pattern when modeling organismenvironment interactions. Ecography 25:616-625

Koopman HN (1998) Topographical distribution of the blubber of harbor porpoises (Phocoena phocoena). J Mammal 79:260-270

Koschinski S, Culik BM, Damsgaard Henriksen O, Tregenza N, Ellis GM, Jansen C, Kathe G (2003) Behavioural reactions of free-ranging porpoises and seals to the noise of a simulated $2 \mathrm{MW}$ windpower generator. Mar Ecol Prog Ser 265:263-273

Krause G, Budeus G, Gerdes D, Schaumann K, Hesse K (1986) Frontal systems in the German Bight and their physical and biological effects. In: Nihoul J (ed) Marine interfaces ecohydrodynamics. Elsevier, Amsterdam, p 119-140

> Legendre P (1993) Spatial autocorrelation: trouble or new paradigm? Ecology 74:1659-1673

Lucke K, Lepper PA, Blanchet MA, Siebert U (2008) Testing the acoustic tolerance of harbour porpoise hearing for impulsive sounds. Bioacoustics 17:329-331

> Lucke K, Siebert U, Lepper P, Blanchet MA (2009) Temporary shift in masked hearing thresholds in a harbor porpoise (Phocoena phocoena) after exposure to seismic airgun stimuli. J Acoust Soc Am 125:4060-4070

MacLeod CD, Weir CR, Pierpoint C, Harland EJ (2007) The habitat preferences of marine mammals west of Scotland (UK). J Mar Biol Assoc UK 87:157-164

Mann K, Lazier J (2006) Dynamics of marine ecosytems. Biological-physical interactions in the oceans. Blackwell Publishing, Malden, MA

Markones N (2007) Habitat selection of seabirds in a highly dynamic coastal sea: temporal variation and influence of hydrographic features. PhD dissertation, University of Kiel

Marubini F, Gimona A, Evans PGH, Wright PJ, Pierce GJ (2009) Habitat preferences and interannual variability in occurrence of the harbour porpoise Phocoena phocoena off northwest Scotland. Mar Ecol Prog Ser 381:297-310

Otto L, Zimmerman JTF, Furnes GK, Mork M, Saetre R, Becker G (1990) Review of the physical oceanography of the North Sea. Neth J Sea Res 26:161-238

Pierpoint C (2008) Harbour porpoise (Phocoena phocoena) foraging strategy at a high energy, near-shore site in south-west Wales, UK. J Mar Biol Assoc UK 88:1167-1173

Pinheiro J, Bates D (2000) Mixed-effect models in S and Splus. Springer, New York, NY

Proelss A, Krivickaite M, Gilles A, Herr H, Siebert U (2011) Protection of cetaceans in European waters - a case study on bottom-set gillnet fisheries within marine protected areas. Int J Mar Coast Law 26:5-45

R Development Core Team (2008) R: a language and environment for statistical computing. R Foundation for Statistical Computing, Vienna. www.R-project.org

$>$ Redfern JV, Ferguson MC, Becker EA, Hyrenbach KD and others (2006) Techniques for cetacean-habitat modeling. Mar Ecol Prog Ser 310:271-295

Redfern JV, Barlow J, Ballance LT, Gerrodette T, Becker EA (2008) Absence of scale dependence in dolphin-habitat models for the eastern tropical Pacific Ocean. Mar Ecol Prog Ser 363:1-14

Richardson WJ, Greene CR, Malme C, Thomson D (1995) Marine mammals and noise. Academic Press, New York, NY

Santos MB, Pierce GJ (2003) The diet of harbour porpoise (Phocoena phocoena) in the Northeast Atlantic. Oceanogr Mar Biol Annu Rev 41:355-390

SCANS-II (2008) Small cetaceans in the European Atlantic and North Sea. Final report to the European Commission under project LIFE04NAT/GB/000245. Sea Mammal Research Unit, Gatty Marine Laboratory, University of St Andrews, St Andrews

Scheidat M, Gilles A, Siebert U (2006) Evaluating the distribution and density of harbour porpoises (Phocoena phocoena) in selected areas in German waters. In: von Nordheim H, Boedeker D, Krause J (eds) Progress in marine conservation in Europe. Springer, Berlin, p 189-208

Scheidat M, Gilles A, Kock KH, Siebert U (2008) Harbour porpoise Phocoena phocoena abundance in the southwestern Baltic Sea. Endang Species Res 5:215-223

Schröder B (2008) Challenges of species distribution modeling belowground. J Plant Nutr Soil Sci 171:325-337

Siebert U, Joiris C, Holsbeek L, Benke H, Failing K, Frese K, Petzinger E (1999) Potential relation between mercury concentrations and necropsy findings in cetaceans from German waters of the North and Baltic Seas. Mar Pollut Bull 38:285-295

Siebert U, Gilles A, Lucke K, Ludwig M, Benke H, Kock KH, 
Scheidat M (2006) A decade of harbour porpoise occurrence in German waters - analyses of aerial surveys, incidental sightings and strandings. J Sea Res 56:65-80

Skov H, Prins E (2001) Impact of estuarine fronts on the dispersal of piscivorous birds in the German Bight. Mar Ecol Prog Ser 214:279-287

Skov H, Thomsen F (2008) Resolving fine-scale spatio-temporal dynamics in the harbour porpoise Phocoena phocoena. Mar Ecol Prog Ser 373:173-186

Teilmann J, Sveegaard S, Dietz R, Petersen IK, Berggren P, Desportes G (2008) High density areas for harbour porpoises in Danish waters. National Environmental Research Institute Tech Rep 657. National Environmental Research Institute, University of Aarhus. Available at www.dmu. $\mathrm{dk} /$ Pub/FR657.pdf

Tougaard J, Carstensen J, Teilmann J, Skov H, Rasmussen P (2009) Pile driving zone of responsiveness extends beyond $20 \mathrm{~km}$ for harbor porpoises (Phocoena phocoena (L.)).

Editorial responsibility: Daniel Palacios,

Pacific Grove, California, USA
J Acoust Soc Am 126:11-14

Vinther M, Larsen F (2004) Updated estimates of harbour porpoise (Phocoena phocoena) bycatch in the Danish North Sea bottom-set gillnet fishery. J Cetacean Res Manag 6: $19-24$

Wilson B, Reid RJ, Grellier K, Thompson PM, Hammond PS (2004) Considering the temporal when managing the spatial: a population range expansion impacts protected areas-based management for bottlenose dolphins. Anim Conserv 7:331-338

Wood S (2006) Generalized additive models: an introduction with R. Chapman \& Hall/CRC, Boca Raton, FL

Wood S (2008) Fast stable direct fitting and smoothness selection for generalized additive models. J R Stat Soc Ser B Stat Methodol 70:495-518

Zuur AF, Ieno E, Elphick C (2010) A protocol for data exploration to avoid common statistical problems. Methods Ecol Evol 1:3-14

Submitted: December 1, 2010; Accepted: March 8, 2011

Proofs received from author(s): July 8, 2011 